http://jmscr.igmpublication.org/home/ ISSN (e)-2347-176x ISSN (p) 2455-0450 crossref DOI: https://dx.doi.org/10.18535/jmscr/v8i4.13

\title{
Role of Multifocal Lenses in achieving spectacle-free vision post-operatively in cataract patients - A prospective Study
}

\author{
Author \\ Dr K.M Suresh, MBBS, MS (OPH) \\ Medical Director Vidya Eye Hospital, Bangalore 560040, India
}

\begin{abstract}
Aim of the study was to find out whether the implantation of the multifocal lenses, can be recommended categorically, to expect a good spectacle-free vision in cataract patients.

Materials and Methods: consisted of a prospective study in which 50 eyes of cataract patients were implanted with multifocal lenses. Criteria like visual improvement, spectacle-free vision, glare, diplopia and de-centration of the lens were used, to assess the result of this prospective study.

Conclusion: The study undoubtedly concluded that implantation of multifocal can be recommended, to expect post-operatively in cataract patients a spectacle-free $6 / 6$ and N5 vision, with a condition that the lens should be heparin surface modified lens, as in our study more than $90 \%$ of the patients achieved unaided 6/6 vision and unaided $N 5$ of near vision.
\end{abstract}

\begin{abstract}
Aim
Aim of this study was to understand the efficacy of multifocal lenses in achieving spectacle free life in cataract patients. Study was to understand the factors responsible, for constant achievement, of unaided 6/6 distant vision, and also unaided N5 near vision, so that the patient can enjoy spectacle free vision postoperatively. Finally, the aim of this study was to categorically decide whether multifocal lenses can be recommended for all the cataract cases with the utmost confidence of achieving a spectacle free life.
\end{abstract}

\section{Materials and Methods}

First 50 cases for which multifocal lens implantation was done were selected for the study. The cases of cataract which were associated with other diseases like diabetic retinopathy, glaucoma, pre-operative iridocyclitis and other associated ocular abnormalities, and ocular diseases were excluded from the study. The cases which could be followed up for two years after the surgery, meticulously were only included in the study.

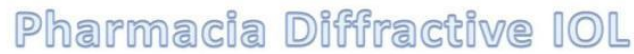

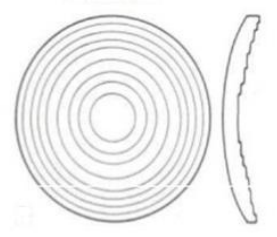

Figure 1 Design of the Multifocal diffractive IOL used in our study.

The cases which were lost in the follow up for two years were obviously excluded from the study. 
Both the cases where in phacoemulsification and SICS were done, were included for the study, anyway the salient differences between the final results of these procedures, were observed, noted and tabulated, so as to enlighten the best choice of operation for the implantation of these multifocal lenses. Comparison between the heparin surface modified lenses and non- heparin surface modified lenses were also made, to understand the preferred choice of multifocal lens that has to be recommended to achieve excellent results in multifocal lens implantation. All the lenses which were implanted were rigid PMMA multifocal lenses. $94 \%$ of the multifocals used in our study were Pharmacia rigid multifocals which were diffractive multifocals which are pupillary size independent and were having concentric grooves on the posterior surface. Sclero- corneal tunnel incision were done in all the cases. All the cases were operated after peribulbar infiltrative anaesthesia with xylocaine $2 \%$ with adrenaline

\section{Results}

In our study $92 \%$ of the patients who underwent multifocal implantation had spectacle free vision for a follow up period of two years. $6 \%$ of the patients had $6 / 18$ unaided vision while $2 \%$ had unaided vision of 6/36. Even in these cases when residual power were corrected for distant vision, not only did the patients got $6 / 6$ distant vision, but they also enjoyed unifocal spectacle correction as it was not necessary for them to wear an additional correction for near vision.

\section{Discussion}

The main reason for this good percentage of success rate was due to the fact that the multifocal lenses used in our study were diffractive multifocals, pupil independent IOLs and heparin surface modified lenses. The main reason for poor vision in the group which had 6/18 vision was due to improper placement of the multifocal IOL in the bag in one case and capsular bag contracture in two cases. Capsular bag contracture were observed in cases where non heparin surface modified lenses were used. Reason for $6 / 36$ vision in the $2 \%$ of the cases is due to astigmatism induced by the intra ocular lens tilt, due to the lens being implanted on the remnants of the capsules due to posterior capsular tear and the resultant vitreous loss, which was adequately treated with anterior vitrectomy before implanting the IOL, on the remnants of the anterior and posterior capsule. It was observed that irido- pseudophakic adhesions, pupillary capture due to contracture of the capsular bag, de-centration and resultant glare, were observed only in implantation of the multifocals which were not heparin surface modified

\begin{tabular}{|l|c|c|}
\hline Complications & $\begin{array}{c}\text { Number of } \\
\text { patients }\end{array}$ & Percentage \\
\hline Aberrations & 0 & 0 \\
\hline Glare & 2 & 4 \\
\hline Halos & 0 & 0 \\
\hline Diplopia & 0 & 0 \\
\hline Difficulty in night Driving & 0 & 0 \\
\hline Poor unaided vision & 4 & 8 \\
\hline Unpleasant Reflexes & 0 & 0 \\
\hline
\end{tabular}

In our study we noticed that in 2 cases complained of glare due to the de-centration of the lens. Poor unaided distant vision were observed in 4 cases. No cases needed an explant due to annoying reflexes or aberrations.

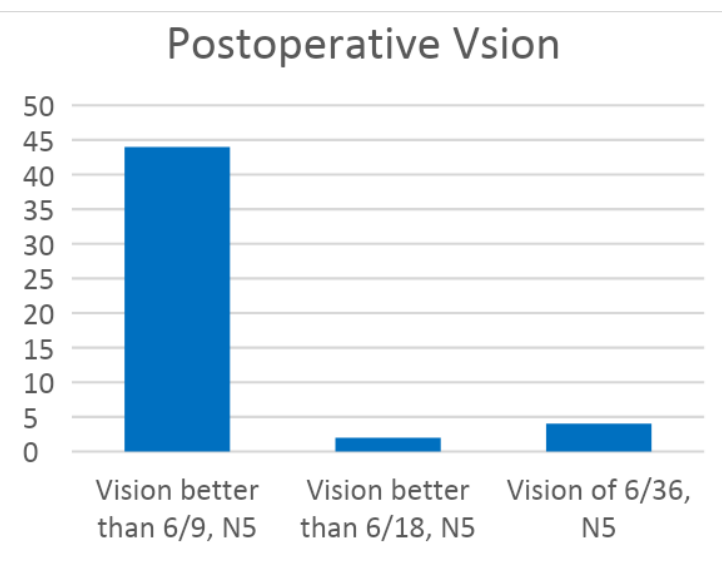

\section{Conclusion}

Multifocal IOLs provide best uncorrected near visual acuity and an appreciably good uncorrected distant vision. These facts were more pronounced and evident, when heparin surface coated lenses 
were used. It was firmly conclusive that phacoemulsification is better than SICS for exclusive implantation of multifocals to expect excellent post- operative visual accuracy, as almost all the cases which underwent phacoemulsification, culminated in 6/6 distant vision and N5 near vision without the aid of spectacle correction. It was also noted in our study that when posterior capsular tear and vitreous loss are present, it is better to abandon multifocal lens implantation. In such cases better to depend on unifocals. In our study Pharmacia company lenses were proved to be the best possible choice in achieving spectacle free post-operative vision. It is imperative to note that heparin surface modification is a must and rather a mandatory condition for implanting the multifocals, as good results were achieved and no complications were encountered in such cases. The study also concluded that in the bag implantation of Intra Ocular Lens which is heparin surface modified is the ideal procedure, to achieve consistent results of spectacle free vision of unaided $6 / 6$ distant and N5 of near vision

\section{References}

1. Congdon N, Vingerling JR, Klein BE, et al. Prevalence of cataract and pseudophakia/aphakia among adults in the United States. Arch Ophthalmol. 2004; 122:487-494. [PubMed].

2. Javitt JC, Wang F, West SK. Blindness due to cataract: Epidemiology and prevention. Ann Rev Public Health. 1996; 17:159-177. [PubMed].

3. Agency for Health Care Policy and Research. Cataract in Adults: Management of functional impairment. Rockville, MD: Agency for Health Care Policy and Research; 1993.

4. Anmarkrund N, Bergaust B, Bulie T, Sand AB. Evaluation of a flexible one-piece open-loop anterior chamber lens Symflex 350B 3-4 years after implantation. Acta Ophthalmol. 1993;71:796-800. [PubMed]
5. Pötzsch DK, Lösch-Pötzsch M. Four year follow-up of the Memorylens. J Cataract Refract Surg. 1996;22:1336-1341. [PubMed].

6. Schmack WH, Gerstmeyer K. Long-term results of the foldable CeeOn edge intraocular lens. J Cataract Refract Surg. 2000;26:1172-1175. [PubMed].

7. Milazzo S, Turut $\mathrm{P}$, Artin B, Charlin JF. Long-term follow-up of threepiece, looped, silicone intraocular lenses. J Cataract Refract Surg. 1996;22 (Suppl 2):1259-1262. [PubMed].

8. Linnola RJ, Holst A. Evaluation of a 3piece silicone intraocular lens with poly(methyl methacrylate) haptics. J Cataract Refract Surg. 1998;24:15091514. [PubMed].

9. Simpson MJ. The diffractive multifocal intraocular lens. Eur J Implant Refract Surg. 1989;1:115-121.

10. Javitt JC, Steinert RF. Cataract extraction with multifocal intraocular lens implantation: A multinational clinical trial evaluating clinical, functional, and qualityof-life outcomes. Ophthalmology. 2000;107:2040-2048. [PubMed].

11. Javitt JC, Wang F, Trentacost DJ, et al. Outcomes of cataract extraction with multifocal intraocular lens implantation: Functional status and quality of life. Ophthalmology. 1997;104:589-599. [PubMed].

12. Rossetti L, Carraro F, Rovati M, et al. Performance of diffractive multifocal intraocular lenses in extracapsular cataract surgery. J Cataract Refract Surg. 1994; 20: 124-128. [PubMed].

13. Vaquero M, Encinas JL, Jimenez F. Visual function with monofocal versus multifocal IOLs. J Cataract Refract Surg. 1996;22: 1222-1225. [PubMed].

14. Gimbel HV, Sanders DR, Raanan MG. Visual and refractive results of multifocal 
intraocular lenses. Ophthalmology. 1991; 98:881-888. [PubMed].

15. Auffarth GU, Dick HB. Multifocal intraocular lenses. A review. Ophthalmologe. 2001;98:127-137. [PubMed].

16. Khoshnood B, Mesbah M, Jeanbat V, et al. Transforming scales of measurement of visual acuity at the group level. Ophthalmic and Physiological Optics. 2010;30:816-823. [PubMed].

17. Mosteller F, Colditz GA. Understanding research synthesis (metaanalysis) Ann Rev Public Health. 1996;17:1-23. [PubMed]

18. DerSimonian R, Laird N. Meta-analysis in clinical trials. Control Clin Trials. 1986;7: 177-188.[PubMed].

19. Bi H, Cui Y, Ma X, et al. Early clinical evaluation of Acrys of ReSTOR Multifocal lens for treatment of cataract. Ophthalmologica. 2008;222:11-16. [PubMed].

20. Chiam PJ, Cahn JH, Haider SI, et al. Functional vision with bilateral Rezoom and ReSTOR intraocular lenses 6 months after cataract surgery. J Cataract Refract Surg. 2007;33:2057-2061. [PubMed].

21. Toto L, Falconio G, Vecchiarino L, et al. Visual performance and biocompatibility of 2 multifocal diffractive IOLs. Sixmonth comparative study. J Cataract Refract Surg. 2007;33:1419-1425. [PubMed].

22. Souza CE, Muccioli C, Soriano ES, et al. Visual performance of Acrysof ReSTOR apodized diffractive IOL: A prospective comparative trial. Am J Ophthalmol. 2006; 141:827-832. [PubMed].

23. Vingolo EM, Grenga P, Iacobelli L, Grenga R. Visual acuity and contrast sensitivity: Acrysof ReSTOR apodized diffractive versus Acrysof SA60AT monofocal intraocular lenses. J Cataract Refract Surg. 2007;33:1244-1247. [PubMed].
24. Alfonso JF, Fernandez-Vega L, Baamonde B, Montés-Mico R. Prospective visual evaluation of apodized diffractive intraocular lenses. J Cataract Refract Surg. 2007;33:1235-1243. [PubMed].

25. Chiam PJT, Chan JH, Aggarwal RK, Kasaby S. ReSTOR intraocular lens implantation in cataract surgery: Quality of vision. J Cataract Refract Surg. 2006;32: 1459-1463. [PubMed]. 